\title{
Can Reputation Ensure Efficiency in the Structured Finance Market?
}

\author{
Mahmoud Elamin \\ Federal Reserve Bank of Cleveland in Cleveland, Ohio, USA \\ Email: mahmoud.elamin@clev.frb.org
}

How to cite this paper: Elamin, M. (2017) Can Reputation Ensure Efficiency in the Structured Finance Market? Theoretical Economics Letters, 7, 49-62. http://dx.doi.org/10.4236/tel.2017.71006

Received: November 15, 2016

Accepted: January 6, 2017

Published: January 10, 2017

Copyright $\odot 2017$ by author and Scientific Research Publishing Inc. This work is licensed under the Creative Commons Attribution International License (CC BY 4.0).

http://creativecommons.org/licenses/by/4.0/ c) (i) Open Access

\begin{abstract}
Structured finance products are opaque and their ratings are unverifiable. Therefore, a credit rating agency (CRA) cannot credibly fully reveal its information about the quality of a rated structured finance project. Can reputation discipline the CRA? I introduce incomplete information about the CRA's type: With some probability, it is a truthful type that always fully reveals its information. The (updated) probability that the CRA is truthful is its reputation. With only two project types and when the CRA's reputation is high enough, an informationally-efficient equilibrium, where investors are fully informed, exists. If firms know the true CRA type however, this existence result fails. Moreover, with more than two project types, no matter how high the CRA's patience level or its reputation, there is no informationally-efficient equilibrium. The many project types case is clearly the relevant case. Therefore, I conclude that the fear to lose reputation is not enough deterrent in the structured finance market.
\end{abstract}

\section{Keywords}

Credit Rating Agencies, Conflicts of Interest, Reputation

\section{Introduction}

The recent financial crisis exposed widespread problems with rating structured finance products. In the aftermath, it became common practice to criticize these ratings, both in the academic literature and the public sphere. US congress conducted hearings questioning credit rating agencies (CRA) behavior. Subsequently, numerous articles lambasted them for the findings. CRAs themselves admitted the deep crisis they face, and acknowledged the need to work on restoring the market's faith and confidence in their ratings' credibility. Empirical literature discussing rating problems exploded. I only discuss some of the earlier papers here: [1] discussed problems with rating timeliness, [2] discussed the "Credit Rating Crisis", and [3] discussed the economics behind CDOs and showed problems with the CRA's models. Theoretical models 
discussing these problems included [4] and [5], among others. [6] is a recent literature review of relevant topics pertaining to this business.

Before the crisis, CRAs insisted adamantly that their business is built on market participants' trust and confidence in their ratings. Their much-repeated claim is that CRAs can not afford to misrate products. If they do, their reputation collapses. Reputation, as the story goes, is the CRA's business main capital. If reputation collapses, ratings have no credibility and market participants would simply ignore them, rendering them irrelevant. This would deal a fatal blow to the CRAs.

More generally, CRAs were thought to mitigate information asymmetries in financial markets. They independently certified information about issuances, revealing relevant information to the public about rated projects default probabilities. Firms in need of financing used the CRAs as a signaling device. Good firms asked to be rated, providing investors with independent certification of their project's quality. But since the financial crisis revealed an across-the-board failure in rating a whole class of assets-structured finance assets-confidence in the CRAs' ability to rate these products was severely damaged. [4] identified a key feature of structured finance products: Their ratings are effectively unverifiable relative to bond ratings. It showed that because of unverifiability, an equilibrium where CRAs fully reveal their information does not exist.

This paper builds on the unverifiable ratings model of [4], and introduces reputation as in [7] and [8]. I evaluate whether the CRA's fear to lose its reputation is potent enough to deter it from misrating structured finance products. I show that reputation is not potent enough to deter CRA from deviating from truth-telling, no matter how high their patience or initial reputation levels. This contrasts with the standard story the CRAs were pushing before the crisis. It also calls for a more cautious approach to structured finance or any other non-verifiable ratings.

The rest of the paper is organized as follows: Section 2 presents the infinitely repeated game with reputation, Section 3 presents the case of two projects but with firms informed of the CRA's type, Section 4 presents the case of more than two projects and Section 5 concludes.

\section{Infinitely Repeated Game with Reputation}

Time is discrete and infinite. Short-run investors, firms, and a long-run CRA with reputation engage in an infinitely repeated game ${ }^{1}$. Every period $t$, a short-run firm (firm $t$ ) needs to fund a project that is either good or bad. Projects differ only in their probability of default, and are ex-post indistinguishable. Both yield $\bar{R}$ if successful, and zero in default. The probability of default is iid across time and comes from the set $\left\{p_{H}, p_{L}\right\}$ with prior $\eta$ on the low quality project $p_{L}^{2}$.

Firms know their project type, and can access a CRA to signal it to investors. The CRA knows the project type if accessed, and rates the project good or bad. The CRA is

\footnotetext{
${ }^{1}$ Firms are short-run as in the structured finance market. The structured securities' payment depends only on cash flows specific to the particular pool of loans that back these securities. Issuers sell the pool of loans to a special purpose vehicle. The special purpose vehicle itself issues structured finance securities backed by the pool, and pays the issuer cash for the sale of loans. The issuer is not liable if the special purpose vehicle defaults.

${ }^{2} 0<p_{H}<p_{L}<1$ and $p_{L}$ is the low quality project.
} 
one of two possible types: A truthful type that always reveals its information truthfully, or a strategic type that rates to maximize its discounted payoffs. Let $0<\alpha_{1}<1$ be the prior probability that the CRA is truthful. Every period, investors and firms use the public history to form a posterior probability that the CRA is truthful. This posterior is the CRA's reputation.

\subsection{Stage Game and Setup}

Every period $t$, a new project is selected for the time $t$ firm. Firm $t$ needs the funding of two short-run investors $t 1$ and $t 2$, alive in that period. Firm $t$ knows its project type and decides whether to access the CRA (A) or not (NA) ${ }^{3}$. If accessed, the CRA sees the project's default probability and makes a public announcement from $\{H, L\}$. The truthful CRA says $H$ after observing a $p_{H}$ project, and $L$ after observing an $p_{L}$ project. Investors form posterior beliefs on default in three possible contingencies: Firm $t$ did not access the CRA, or it did and $H$ or $L$ were announced. Let $\mu($.$) be the probability that the project is the bad type, given the history$ observed up to time $t$, the strategies of the CRA and firm $t$, and the contingency that the investor find themselves in.

Investors are identical with $\log$ utility, and an endowment of one unit of a good. They simultaneously make offers $\left(R_{t i}, b_{t i}\right)$, where $R_{t i} \in \Re$ is investor ti's required return and $0 \leq b_{t i} \leq 1$ is his demanded issuance size. The issuance size determines the exposure to the risky project. What remains of the endowment after the issuance size is deducted will be consumed for sure, irrespective of the project's success or default. Investor offers depend on their beliefs about the default probability.

Firm $t$ then picks the best offer. When indifferent, it picks each with probability $\frac{1}{2}$. When the CRA is not accessed, all the issuance size $b$ is invested in the project. When accessed, the CRAs payment is deducted from the issuance size upfront before any investment is made. Only $(1-\epsilon) b$ is invested in the project, and $\epsilon b$ is paid to the CRA upfront. Then, the project either defaults or pays, and the period $t$ game ends. The next period $t+1$ starts with the same CRA, a different firm with a new project (firm $t+1)$ and two new investors $(t+1,1$ and $t+1,2)$. A detailed timeline of the events can be found in Appendix A3.

\subsection{Payoffs}

An unpicked investor always consumes his endowment and gets zero utility. If the CRA was not accessed at time $t$, the picked investor $t i$ consumes $1-b_{t i}$ when the project selected at time $t$ defaults, and $1-b_{t i}+R_{t i} b_{t i}$ when the project pays. If the CRA was accessed, the picked investor $t i$ consumes $1-b_{t i}$ when the project defaults, and $1-b_{t i}+R_{t i}(1-\epsilon) b_{t i}$ when the project pays.

Assume the selected offer in period $t$ is $\left(R_{t i}, b_{t i}\right)$. Firm $t$ earns zero profit when the project defaults (limited liability) and if the project pays it earns: $\left(\bar{R}-R_{t i}\right) b_{t i}$, if the CRA was not accessed in period $t$ and $(1-\epsilon)\left(\bar{R}-R_{t i}\right) b_{t i}$, if the CRA was accessed in period $t$. The truthful CRA has a dominant strategy to act truthfully. The payoff of the

${ }^{3}$ Denote the access action by $a_{t}$ and let $a_{t}=0$ if firm $t$ did not access the CRA at time $t$, and $a_{t}=1$ if it decides to access. 
strategic CRA with discount factor $0<\delta<1$ is the discounted sum of its one period payoff. Let the selected issuance size in period $t$ be $b_{t}$ and let $a_{t}$ be the indicator function of the access decision by firm $t$ as explained before. The strategic CRA's payoff from the sequence $\left\{b_{t}\right\}_{t=1}^{\infty}$ is: $(1-\delta) \sum_{t=1}^{\infty} a_{t} \delta^{t-1} \epsilon b_{t}$.

\subsection{Equilibrium Characterization}

The equilibrium concept I use is the Perfect Public Equilibrium (PPE) $)^{4}$. To make the game interesting, I assume the investor still invests some of his endowment in the bad project, even when the the CRA is accessed.

Condition 1. $p_{L}<\frac{(1-\epsilon) \bar{R}-1}{(1-\epsilon) \bar{R}}$

Next, I assume the CRA's fee is small enough that firms prefer to access and pool than not access and be considered bad. Let $q=\eta p_{L}+(1-\eta) p_{H}$ be the posterior on default under the prior. The profits when investors retain their priors after access is higher than the profits when the CRA is not accessed and the firm is considered to be bad.

Condition 2. $(1-\epsilon) \bar{R}-\frac{((1-\epsilon) \bar{R}-1)^{q}}{(1-q)^{1-q} q^{q}}>\bar{R}-\frac{(\bar{R}-1)^{P_{L}}}{\left(1-p_{L}\right)^{1-P_{L}} p_{L}^{P_{L}}}$

I work my way backwards from the end of the period. Investors are short-run, and only care for their period payoff. The PPE admits on the equilibrium path beliefs that are derived from strategies by Bayes Rule. Off the equilibrium path, there is no restriction on admissible beliefs. The following Lemmas pin down investors' optimal strategies given these beliefs. The proofs for these Lemmas can be found in [4]. This paper and [4] differ in the way the beliefs are formed. Here the CRA has a reputation, and the posterior beliefs are computed differently. But notwithstanding how beliefs are formed, optimal investor best responses given beliefs are the same.

Lemma 1. Under Condition 1 and Condition 2, and given $\mu$ (the belief in these contingencies that the project is bad),

1. An optimal response of the investors given beliefs in the contingency following access and announcement is a vector $\left(\left(R_{1}, b_{1}\right),\left(R_{2}, b_{2}\right)\right)$ for the two investors s.t. for $i \in\{1,2\},\left(R_{i}, b_{i}\right)$ solves the following problem (Problem $\left.P 1\right)$ :

$$
\begin{gathered}
(1-\epsilon) \operatorname{Max}_{R_{i}, b_{i}}\left(\bar{R}-R_{i}\right) b_{i} \text { s.t. } \\
0 \leq b_{i} \leq 1 \\
q \log \left(1-b_{i}\right)+(1-q) \log \left(1+\left(R_{i}(1-\epsilon)-1\right) b_{i}\right)=0
\end{gathered}
$$

where:

$$
q=\mu(A, L) p_{L}+(1-\mu(A, L)) p_{H} \text { if there was access and } \mathrm{L} \text { was announced. }
$$

$q=\mu(A, H) p_{L}+(1-\mu(A, H)) p_{H}$ if there was access and $\mathrm{H}$ was announced.

2. An optimal response of the investors given beliefs in the contingency following no access is a vector $\left(\left(R_{1}, b_{1}\right),\left(R_{2}, b_{2}\right)\right)$ for the two investors s.t. for $i \in\{1,2\}, \quad\left(R_{i}, b_{i}\right)$

${ }^{4}$ Every equilibrium discussed in this paper also satisfies the requirements of a sequential equilibrium. Because the main results are essentially non-existent results, to get a stronger result, I use the less restrictive concept of PPE. 
solves the following problem (Problem $P 2$ ):

$$
\begin{gathered}
\operatorname{Max}_{R_{i}, b_{i}}\left(\bar{R}-R_{i}\right) b_{i} \text { s.t. } \\
0 \leq b_{i} \leq 1 \\
q \log \left(1-b_{i}\right)+(1-q) \log \left(1+\left(R_{i}-1\right) b_{i}\right)=0
\end{gathered}
$$

where:

$$
q=\mu(N A) p_{L}+(1-\mu(N A)) p_{H}
$$

Lemma 2. Under Condition 1 and Condition 2, there exists a solution $(R, b)$ that solves P1. Moreover the solution is unique and is characterized by the following two equations:

$$
\begin{aligned}
& b=1-\left[\frac{q}{(1-q)((1-\epsilon) \bar{R}-1)}\right]^{1-q} \\
& R=\frac{1}{q}\left[(1-q) \bar{R}-\frac{1}{(1-\epsilon)}\right] \frac{1-b}{b}
\end{aligned}
$$

Lemma 3. Under Condition 1 and Condition 2, there exist a solution $(R, b)$ that solves P2. Moreover, the solution is unique and is characterized by the following two equations:

$$
\begin{aligned}
& b=1-\left[\frac{q}{(1-q)(\bar{R}-1)}\right]^{1-q} \\
& R=\frac{1}{q}[(1-q) \bar{R}-1] \frac{1-b}{b}
\end{aligned}
$$

The Lemmas fully detail the optimal investor response, and computes the exact offers investors offer, given their beliefs. This allows us to compute the CRA's payoff when accessed, and to work our way backwards to compute optimal strategies for the CRA and the firm.

\subsection{Informationally-Efficient Equilibrium}

The main question this paper seeks to answer is: Will reputation ensure truth-telling in the structured finance market? If CRAs are truthful, then there is a possibility that incomplete information about the project type would be eliminated. The CRA is fully informed of the project type, when accessed by a firm. Its role is to mitigate the information asymmetry between firms and investors. I consider a notion of efficiency where the CRA fully fulfills its role revealing all the information it has about the projects it rates when accessed. Intuitively speaking, in an informationally-efficient equilibrium, investors are always informed of the type of project they face, and there is no information asymmetry.

Definition 1. A PPE is informationally-efficient if, on the equilibrium path, investors are correct in their beliefs about the type of project they face.

The first result of this paper is that there is an informationally-efficient equilibrium, when there are only two kinds of projects, if reputation is high enough. I first identify a 
threshold for reputation to exceed for the equilibrium to exist. Define the reputation value $\alpha^{*}$ at which the bad firm is indifferent between access and no access, when the strategic CRA says it is the good firm after it accesses, and the investors believe the CRA, and the bad firm is known to be the bad firm when it does not access. The bad firm faces a tradeoff between accessing, paying the CRAs fee, and be considered the good firm, and between not accessing, saving the fee, and be considered the bad firm. $\alpha^{*}$ is the level of CRA reputation at which the bad firm is indifferent between these two alternatives. When the CRA's reputation exceeds this cutoff, the bad firm would not access the CRA.

Let $\alpha^{*}$ be the $0<\alpha<1$ that solves the following equation ${ }^{5}$ :

$$
\begin{aligned}
& \alpha\left[(1-\epsilon) \bar{R}-\frac{((1-\epsilon) \bar{R}-1)^{p_{L}}}{\left(1-p_{L}\right)^{1-P_{L}} p_{L}^{P_{L}}}\right]+(1-\alpha)\left[(1-\epsilon) \bar{R}-\frac{((1-\epsilon) \bar{R}-1)^{p_{H}}}{\left(1-p_{H}\right)^{1-p_{H}} p_{H}^{P_{H}}}\right] \\
& =\bar{R}-\frac{(\bar{R}-1)^{p_{L}}}{\left(1-p_{L}\right)^{1-p_{L}} p_{L}^{P_{L}}}
\end{aligned}
$$

Proposition 1. Under Condition 1 and Condition 2, independent of the discount factor $0 \leq \delta<1$, if the prior reputation is greater than the reputation cutoff $\left(\alpha_{1} \geq \alpha^{*}\right)$ then there is an informationally-efficient equilibrium. If $\alpha_{1}<\alpha^{*}$ then there is no informationally-efficient equilibrium.

Proposition 1 showed that there is an informationally-efficient equilibrium when there are only two types of projects and the reputation level is high enough. The intuition is very simple. Assume that the reputation of the CRA is almost 1. Bad firms would not want to access, and good firms would want to access. Access by the bad firms would almost surely reveal they are the bad firms. The worst that could happen if they do not access is that they are considered to be the bad firms. But even then, they save the fee. The good firms, on the other hand, would want to access because that almost surely signals they have the good project. When the good firms access and the bad firms do not, the reputation level stays constant in the game ${ }^{6}$.

The remaining of this paper is an assessment of the robustness of this result. First, is it robust to changes in the information structure of the game? Second, does the result extend to when the number of projects increase to more than two? The infromationally-efficient equilibrium is not robust to these two very natural extensions. Proposition 2 answers the first question in the negative, and Proposition 3 answers the second question in the negative. The informationally-efficient equilibrium exist because there are only two project types, and the access/no access decision itself is enough to separate the types, irrespective of the CRA's actions.

\section{Firms Informed of CRA's Type}

This section motivates the first robustness question and checks if the existence result

${ }^{5}$ I note that under Condition 1 and Condition 2, a solution $\alpha^{*}$ to the above equation exists by the intermediate value theorem. Moreover the solution $\alpha^{*}$ is unique because of monotonicity in $\alpha$ of the LHS of the equation.

${ }^{6}$ Firms profits are higher when they access, pay the fee, and are thought to be the good firms rather than not access, save the fee, and are thought to be the bad firms. 
obtained in Proposition 1 extends to the case where the firms are informed of the CRA's type. CRAs operate under what is known as the issuer-pays business model. Issuers of the securities themselves pay the CRA raising some doubts about their clout with the CRA. But generally, economist tend to analyse the incentive structure itself and not who pays for the access decision. In other words, what is important is based on what is the CRA paid and not on who pays it. More importantly, the process of rating a security is a give and take process between the issuer of the security and the CRA. There is a high level of interaction between the firms and the CRA. This interaction endows the firm with a deeper knowledge of the CRA's inner workings. I adjust the information structure to account for these close interactions, the firms now know the CRA's true type. They know the CRA is strategic, when it is. They know it is truthful, when it is. The investors still have incomplete information about the CRA's type, because they are far removed from direct dealing with the CRA. Investors see the CRA as a black box which issues ratings. By the equilibrium definition they know which strategy each type uses, but they do not know which type is the true type. Will the existence result of Proposition 1 hold in this environment ${ }^{7}$ ?

Proposition 2. Under Condition 1 and Condition 2, if firms are informed of the CRA's true type, then for every discount factor $\delta: 0 \leq \delta<1$ and for every initial reputation level $\alpha: 0 \leq \alpha_{1}<1$ there is no informationally-efficient equilibrium.

\section{Proof.}

For an informationally-efficient equilibrium to exist, it has to be the case, that the investors are informed of the true type of the project in every possible situation. In particular, this has to hold when the CRA is strategic. In this case, both the firms and the CRA know it is strategic, while the investors believe it is truthful with some probability. The only way an informationally-efficient equilibrium would exist in this case is that the CRA would mimic the truthful CRA. Now assume that is the case and I will show a profitable deviation that would unravel the possibility that this is an equilibrium. The arguments in the proof of Proposition 1 show that the case to consider is where the good firm accesses and is revealed to be the good firm, and the bad firm does not access.

Assume the CRA has threatened the bad firm by revealing its type when it is the strategic type with high enough probability to convince it not to access. And if this is part of an equilibrium, then the investors are certain that the bad firm would never access. Any access decision by a firm is then interpreted by the investors to be that the firm is good. But then no matter what the strategic CRA said it will do, it will always say the project is good when accessed by the bad firm. This increases the CRAs payoff, and definitely increases the firm's payoff. Therefore, the equilibrium unravels and our Proposition is proved.

Proposition 2 shows that if firms are informed of the type of the CRA, there is no informationally-efficient equilibrium and the CRA can not fulfill its role and mitigate information asymmetry.

${ }^{7}$ I will skip making the adjustments to the strategies of the firms and to the equilibrium concept because these adjustments are straightforward. 


\section{More than Two Project Types}

This section checks if the existence of an informationally-efficient equilibrium when reputation is high enough in Proposition 1 extends to the case of more than two projects. Obviously, in reality there are more than two project types, and I now consider this more realistic case. Here, only the CRA knows its type. The investors and firms have to use the public history to update their probability that the CRA is the truthful type.

I now make the necessary changes to Condition 2 and quickly sets up the new game. Assume there are $N$ projects with $N$ different probabilities of default $p_{1}<p_{2}<\cdots<p_{N}$. Let $N \geq 3$. Also assume the prior on each project is $\eta_{n}>0$ where $\sum_{n=1}^{N} \eta_{n}=1$. A time $t$ public history becomes an element $h_{t}^{p} \in\left[\{N A,(A, 1),(A, 2), \cdots,(A, N)\} \times \mathfrak{R}^{2} \times[0,1]^{2} \times\{1,2\} \times\{D, P\}\right]^{t-1}$. Firm $t$ 's strategy becomes $\sigma_{\text {Firm } t}: H_{t}^{p} \times\left\{p_{1}, \cdots, p_{N}\right\} \rightarrow \Delta\{A, N A\}$ and the CRA's strategy becomes $\sigma_{\text {CRA }}: \zeta_{0} \times H^{p} \times A \times\left\{p_{1}, \cdots, p_{N}\right\} \rightarrow \Delta\{1, \cdots, N\}$. Investor $t i$, sees the public history from the past and picks his offer given the $N+1$ contingencies he might find himself in today. Time $t$ investor $i$ 's strategy is $\sigma_{t i}: H_{t}^{p} \times\{N A,(A, 1), \cdots,(A, N)\} \rightarrow \mathfrak{R} \times[0,1]$.

The condition imposed on this environment will allow the before-worst firm to get higher profits when it accesses the CRA and its true type is revealed than not access and be considered the worst firm.

Condition 3. $(1-\epsilon) \bar{R}-\frac{((1-\epsilon) \bar{R}-1)^{P_{N-1}}}{\left(1-p_{N-1}\right)^{1-P_{N-1}} p_{N-1}^{P_{N-1}}} \geq \bar{R}-\frac{(\bar{R}-1)^{P_{N}}}{\left(1-p_{N}\right)^{1-p_{N}} p_{N}^{P_{N}}}$

Condition 3 is in line with our informationally-efficient equilibrium definition. If this condition does not hold there is no hope of getting an informationally-efficient equilibrium since the before-worst firm would never access and pay the fee to reveal its type. It does that since it prefers to always not access and save the fee. But then the worst and the before-worst firm pool together and no informationally-efficient equilibrium exists. I also note here that if this condition holds for the before-worst firm, then it holds for every firm that has a better project. Hence when Condition 3 holds, every firm other than the worst firm prefers to access and pay the fee when their true type is revealed than not access and save the fee, but be considered the worst firm.

To prepare for the proof of Proposition 3, for $n \neq N$ let $b_{n}^{*}$ be the optimal issuance size investors are willing to buy after access when they know that they face the project with default $p_{n}$. From Lemma 2 it is clear that $b_{n}^{*}=1-\left[\frac{p_{n}}{((1-\epsilon) \bar{R}-1)\left(1-p_{n}\right)}\right]^{1-P_{n}}$. I remind the reader that $b_{1}^{*}>b_{2}^{*}>\cdots>b_{N-1}^{*}$. The optimal issuance size increases when the investors know that they face a less risky project.

Proposition 3. Under Condition 1 and Condition 3, in the infinitely repeated game with reputation if the number of projects is more than two, then independent of the discount factor $\delta: 0 \leq \delta<1$ and the initial reputation level $\alpha_{1}: 0 \leq \alpha_{1}<1$ there is no informationally-efficient equilibrium.

Proof. 
I first note that a bad firm will never access if its true type is revealed. No access is always a profitable deviation. When it does not access, the worst the investors could believe about the firm is that it is the bad firm. But even then the bad firm saves the fee. So in an informationally-efficient equilibrium the bad firm will not access the CRA. Now note that an informationally-efficient equilibrium separates between the types on the equilibrium path. Hence in an informationally-efficient equilibrium all the firms with types better than the worst will access and the CRA will reveal their type truthfully.

I note now that everything in the paragraph above has got to happen in every time period along the equilibrium path. Now fix the first period of an informationallyefficient equilibrium and let us look at the continuation payoffs from period $2 \mathrm{on}$. In every contingency along the equilibrium path every firm better than the worst will access and its type will be revealed to the investors. Hence the continuation payment of the CRA after every contingency that happens on the equilibrium path is constant and in particular is equal to $\frac{\sum_{n=1}^{N-1} \eta_{n} \epsilon b_{n}^{*}}{1-\delta}$.

Therefore, the continuation from period 2 onwards is fixed at $\frac{\sum_{n=1}^{N-1} \eta_{n} \epsilon b_{n}^{*}}{1-\delta}$ and that all the firms except the worst firm will access and their true type will be revealed. Consider the following profitable deviation for the CRA, after access by a $p_{2}$ firm, it announces it is a $p_{1}$ firm. The investor would assume play is still on the equilibrium path and would act accordingly increasing the CRA's current payment $\left(\epsilon b_{1}^{*}>\epsilon b_{2}^{*}\right)$, and the future payment is still fixed by the equilibrium's continuation payment $\left(\frac{\sum_{n=1}^{N-1} \eta_{n} \epsilon b_{n}^{*}}{1-\delta}\right)$. This profitable deviation concludes our simple proof.

\section{Conclusion}

In this paper I have shown that reputation is not potent enough for the CRA to mitigate information asymmetry in the structured finance market. In the model with reputation, it is expected that the fear to lose this reputation will discipline the CRA and help it fulfill its role fully. This logic does not seem to work with unverifiable ratings. More generally, the results of this paper, point to the importance of verifiability in solving agency problems at the credit rating industry. The innovation of this paper is to provide limitations on the potency of reputation in solving agency problems.

\section{Acknowledgments}

The author is grateful to Christopher Phelan, Jan Werner, David Rahman, and Aldo Rustichini for advice and suggestions, seminar participants at University of Minnesota, Cleveland fed, Ryerson University, Monash University, University of Sydney, Midwest Economic Conference, Kent State University, and American University of Beirut for helpful comments. The views expressed herein are those of the authors and not necessarily those of the Federal Reserve Bank of Cleveland or the Federal Reserve System. 


\section{References}

[1] Gu, J., Jones, J. and Liu, P. (2014) Do Credit Rating Agencies Sacrifice Timeliness by Pursuing Rating Stability? Evidence from Equity Market Reactions to CreditWatch Events. Theoretical Economic Letters, 4, 311-322. https://doi.org/10.4236/tel.2014.45042

[2] Benmelech, E. and Dlugosz, J. (2009) The Credit Rating Crisis. NBER Macro Annual, 24, 161-207.

[3] Coval, J., Jurek, J. and Stafford, E. (2008) The Economics of Structured Finance. Journal of Economic Perspectives, 23, 3-25. https://doi.org/10.2139/ssrn.1287363

[4] Elamin, M. (2013) Believe Only What You See: Credit Rating Agencies, Structured Finance, and Bonds. Banks and Bank Systems, 8, 79-93.

[5] Mathis, J., McAndrews, J. and Rochet. J.-C. (2009) Rating the Raters: Are Reputation Concerns Powerful Enough to Discipline Rating Agencies? Journal of Monetary Economics, 56, 657-674. https://doi.org/10.1016/j.jmoneco.2009.04.004

[6] Jeon, D.-S. and Lovo, S. (2013) Credit Rating Industry: A Helicopter Tour of Stylized Facts and Recent Theories. International Journal of Industrial Organization, 31, 643-651. https://doi.org/10.1016/j.ijindorg.2013.02.004

[7] Milgrom, P. and Roberts, J. (1982) Predation, Reputation, and Entry Deterrence. Journal of Economic Theory, 27, 280-312. https://doi.org/10.1016/0022-0531(82)90031-X

[8] Kreps, D. and Wilson, R. (1982) Reputation and Imperfect Information. Journal of Economic Theory, 27, 253-279. https://doi.org/10.1016/0022-0531(82)90030-8 


\section{Appendix}

\section{A1. Proof of Proposition 1}

Proof. Let us prove the first part of the proposition first. Assume $\alpha_{1} \geq \alpha^{*}$ and $0 \leq \delta<1$. The following is an informationally-efficient equilibrium. Good firms access, and bad firms do not. The strategic CRA always says $L$ (good) after access by $p_{L}$ firm and by $p_{H}$ firm. Beliefs of investors after they see no access is that it is the bad firm, after they see access and $L$ that it is the good firm, and after they see access and $H$ that it is the bad firm. Reputation level stays constant at $\alpha_{1}$ on the equilibrium path, and goes to 1 if the investors see access and $H$ and stays at 1 forever. This proves the first part of the Proposition.

Now to prove the second part, assume there is an informationally-efficient equilibrium and $\alpha_{1}<\alpha^{*}$. There are three cases to consider. First, at any time period the bad firm accesses and it is revealed to be the bad firm and the good firm does not access. That would never arise because the bad firm would profitably deviate to no access. Second, at any time period both types of firms access and the CRA truthfully reveals the types. This case would never arise either. The bad firm would prefer to deviate to no access. The worst that could happen when the bad firm does not access is that it is thought to be the bad firm. But even then, it saves the fee. These two cases show that the bad firm would never access when its true type is revealed after access.

To prepare for the third case I need to understand the possible CRA's continuation payoffs in an informationally-efficient equilibrium. It might be useful at this point to review the comments after Definition 2. The two cases discussed before show that the bad firm would never access in an informationally-efficient equilibrium. Hence to separate the types in an informationally-efficient equilibrium, the good firm has to accesses and the CRA reveals the true type of the project. Notice that because of the definition of an informationally-efficient equilibrium, the good firm has to access every period after every possible contingency. This means that in any informationallyefficient equilibrium the continuation payoff of the CRA on the equilibrium path is fixed no matter what happens today. At any period, the continuation payoff of an informationally-efficient equilibrium is determined by the expected payments coming from access by good firms from that period on. Hence let $b_{L}^{*}$ be the optimal issuance size investors are willing to buy after access when they know that they face the project with default $p_{L}$ (the good project). From Lemma 2 I know that $b_{L}^{*}=1-\left[\frac{p_{L}}{((1-\epsilon) \bar{R}-1)\left(1-p_{L}\right)}\right]^{I-P_{L}}$. The continuation payoff after every possible contingency in an informationally-efficient equilibrium is fixed at $\frac{\eta \epsilon b_{L}^{*}}{1-\delta}$.

In the third case, bad firms do not access and good firm access. The strategic CRA says $L$ (good) after access by good firm, and threatens the bad firm with enough punishment to force it not to access. But no matter what the strategic CRA says it will do after access by $p_{H}$ (bad) firm, consider the following profitable deviation: The bad firm accesses and the CRA says $L$ (good). The unsuspecting investors think they are on the equilibrium path where only good firms access. After access and an $L$ anno- 
uncement by the CRA, the investors believe the project is good giving offers accordingly. The reputation level stays the same, and the CRA and the bad firm both profit from the (wrong) belief of the investor that the project is good. The bad firm gets higher profits because it is thought to be the good firm (by Condition 2 and the monotonicity of profits in beliefs). The CRA's continuation payoff is fixed from

tomorrow on at $\frac{\eta \epsilon b_{L}^{*}}{1-\delta}$ no matter what it says today. With this deviation it gets $\epsilon b_{L}^{*}$, which is the highest payment it could get in a period, and the continuation is constant. Hence the total payment is definitely higher than saying bad, getting the fee for a bad project today and getting the same continuation payoff from tomorrow on. The proposed equilibrium unravels. This concludes our proof.

\section{A2. Histories, and Strategies.}

I now define the relevant histories of the infinitely repeated game necessary to define the strategies of the players. At any time period $t$, a player's strategy might possibly depend on anything he knows at that period of what has transpired in the past, be it private (like the true type of the project for a CRA that was accessed in some previous period) or public (like the decision to access the CRA or not, or if the project defaulted or paid). But here I impose the standard restriction that the players use the past in one way only: The players only use the public events from the past in their strategies. The players can still make their strategy today depend on what they see privately today, but it can depend on the past only through what is publicly known. There is an exception to this of course and that is that the CRA knows what type it is when it moves. At any time period, the CRA knows the move of nature on its type and uses the public history from the past and what it sees privately today when it picks a strategy. Hence, I will first define the public history, and then for each player add to it what he observes privately today and for the CRA its type. Note here that for simplicity, I will not mention the firm $t$ 's second move because as in the Lemmas in Elamin (2010a) in any equilibrium the firm will not move again, and these nodes will be off-path. Tracking behavior in these nodes will be merely cumbersome with no real benefit. The Lemmas derived in Elamin (2010a) still apply to this environment with almost no change in the formulation or the proofs. The only difference is that the beliefs themselves might be different, but behavior given beliefs is still the same. These Lemmas are listed in this paper as Lemmas 1, 2, and 3.

\section{a) Public History}

At any time period $t$, the entries recorded in the public history are the following elements: If the CRA was accessed or not by firm $t$, the public announcement if accessed, the offers of the investors, the chosen investor, and the realization of the project at the end of the period.

A time $t$ public history is an element:

$$
h_{t}^{p} \in\left[\{N A,(A, H),(A, L)\} \times \Re^{2} \times[0,1]^{2} \times\{1,2\} \times\{D, P\}\right]^{t-1}
$$

where:

- NA stands for CRA not accessed.

- $\{(A, H),(A, L)\}$ denotes the decision to access the CRA and the subsequent 
announcement.

- $\mathfrak{R}^{2} \times[0,1]^{2}$ denotes the set of possible required rates and possible issuance sizes of investors $t 1$ and $t 2$.

- $\{1,2\}$ denotes the set of possible chosen investor in each period.

- $\{D, P\}$ denotes the set of what could happen to the project. It either defaults (D) or pays $(\mathrm{P})$.

Let $h_{1}^{p}=\varnothing, H_{t}^{p}$ be the space of all possible time $t$ public histories $h_{t}^{p}$ and $H^{p}=\bigcup_{t} H_{t}^{p}$

\section{b) Strategies}

Firm $t$, sees the public history from the past and the true project type at period $t$ and randomizes on access and not access. Firm $t$ 's strategy is a function $\sigma_{\text {Firm } t}: H_{t}^{p} \times\left\{p_{H}, p_{L}\right\} \rightarrow \Delta\{A, N A\}$. The CRA sees a private history in the time periods it was accessed. The CRA, knowing its type, only uses the public history from the past for its strategy. It specifies what it will do after access by a $p_{H}$ firm and a $p_{L}$ firm. The CRA's strategy is $\sigma_{\mathrm{CRA}}: \zeta_{0} \times H^{p} \times A \times\left\{p_{H}, p_{L}\right\} \rightarrow \Delta\{H, L\}$. Investor $t i$, sees the public history from the past and picks his offer given the three contingencies he finds himself in. Time $t$ investor $i$ 's strategy is $\sigma_{t i}: H_{t}^{p} \times\{N A,(A, H),(A, L)\} \rightarrow \mathfrak{R} \times[0,1]$. Investor $t i$ picks his required rate of return and the issuance size given what he knows up to then.

\section{A3. Timeline}

To make visualizing the game easier a detailed chronological timeline follows.

1. At the beginning of time, Nature picks a type for the CRA and only informs the CRA of it. The CRA is either a strategic type $\zeta_{0}$ or a truthful type $\zeta_{T}$.

2. Then at every period $t$, Nature moves and picks a time $t$ project from the set of possible default probabilities $\left\{p_{H}, p_{L}\right\}$ with prior $\eta$ on $p_{L}$ where $0<p_{H}<p_{L}<1$ and $p_{L}$ is the low quality project.

3. Firm $t$ sees the move of nature and then decides to access (A) the CRA or not access (NA).

4. If accessed by firm $t$, the CRA sees the move of nature on project type in that period and makes a public announcement from the set $\{H, L\}$.

5. Two investors $t 1$ and $t 2$ each with an endowment of one unit of a good, simultaneously make offers $\left(R_{t i}, b_{t i}\right)$ in the following three possible contingencies: Firm $t$ did not access the CRA, it accessed the CRA and $\mathrm{H}$ was announced, or it accessed the CRA and $\mathrm{L}$ was announced. Note that $R_{t i}$ is the required rate of return required by investor $t i$, a real number in $\mathfrak{R}$ and $b_{t i}$ is the issuance size $t i$ is willing to buy where $0 \leq b_{t i} \leq 1$.

6. In all contingencies, firm $t$ observes the offers $\left\{\left(R_{t 1}, b_{t 2}\right),\left(R_{t 2}, b_{t 2}\right)\right\}$ set by the investors playing in period $t$. If the offers give the firm the same profits then Nature moves again picking each offer with probability $\frac{1}{2}$. If the offers give the firm different profits, then the firm decides which offer to pick.

7. Let $b_{t}$ be the issuance size of the picked offer. If the firm has decided to access the CRA then the amount $(1-\varepsilon) b_{t}$ is invested in the project, and the amount $\epsilon b_{t}$ is paid to the CRA upfront. If the CRA was not accessed then $b_{t}$ is invested in the project. 
8. The time $t$ project realizes as a public outcome, it either defaults or pays. Investors $t 1$ and $t 2$ consume and exit the game.

9. The time $t$ game ends. And period $t+1$ starts with two new investors, a new firm with a new project and the same long-run CRA.

Submit or recommend next manuscript to SCIRP and we will provide best service for you:

Accepting pre-submission inquiries through Email, Facebook, LinkedIn, Twitter, etc. A wide selection of journals (inclusive of 9 subjects, more than 200 journals)

Providing 24-hour high-quality service

User-friendly online submission system

Fair and swift peer-review system

Efficient typesetting and proofreading procedure

Display of the result of downloads and visits, as well as the number of cited articles

Maximum dissemination of your research work

Submit your manuscript at: http://papersubmission.scirp.org/

Or contact tel@scirp.org 